[Philips, D. (1999). Recent Developments in National Assessment Policy in Education. New Zealand Annual Review of Education, 8, 147-166]

\section{Recent Developments in National Assessment Policy in Education}

\section{DAVID PHILIPS}

\section{Abstract:}

This paper focuses on national developments in assessment policy during 1998 and early 1999. It describes current curriculum and assessment policy in New Zealand for the compulsory education sector, including requirements for schools, and assessment programmes which provide information on the achievement of individual students, whole cohorts of students, and samples of students for system-wide overviews. Three different kinds of monitoring of school effectiveness are also considered. The second half of the article focuses on the Government's recent Green Paper, Assessment for Success in Primary Schools, which proposed a package of four kinds of assessment activities to fill identified information gaps. After discussing some of the issues raised by the primary education sector about the Green Paper, some unresolved policy issues and possible future directions for a comprehensive national assessment policy are outlined.

$\mathbf{N}$ tional assessment policyis concerned with ensuring that policies and programmes are developed which will contribute to the realisation of the Government's educational goals, especially those concerned with raising student achievement. It also involves consideration of the different purposes for gathering information on student achievement, how teachers' knowledge and skills in conducting assessment can be enhanced, and the legislative and resourcing mechanisms required to ensure that sound practice occurs. During 1998, the key question underpinning work on national assessment policy was "What kinds of information do schools (including teachers, principals, and Boards of Trustees), parents/caregivers, and the Government need to be assured that students are learning, and that their achievement is being effectively monitored against the achievement objectives in the
New Zealand Curriculum?" This has involved identifying the information needs particular to different stakeholders, and evaluating whether the current range of assessment tools is sufficient to provide appropriate information. As a consequence, consideration has been given to the potential role of "externally referenced" information on student achievement (showing the achievement of students compared with that of a national sample or cohort, or various subgroups of similar students) as a complementary source of data to that generated within a school.

To put this issue in context, the paper provides an account of existing curriculum and assessment policy for the compulsory education sector, which includes a range of current requirements for schools, and different layers of assessment, such as assessment of individual students, whole cohorts of students and samples of students for systemwide information on achievement trends. The Government's Green Paper, Assessment for Success in Primary Schools, identified gaps in the kinds of information available on student achievement and proposed a package of four kinds of assessment activities to fill these gaps. The proposals and the associated consultation with the education sector from mid-1998 are also outlined. Finally, something is given of the flavour of the submissions received on the Green Paper, and feedback from a National Assessment Reference Group established by the Ministry in late 1998.

\section{Current Curriculum and Monitoring Requirements}

I shall first provide an overview of the policy context within which assessment policy sits. The New Zealand curriculum currently being developed and implemented in schools has a heightened emphasis on student achievement, compared with previous syllabuses. This is part of the Government's strategy to raise levels of achievement to ensure that students will be better prepared to take their place in the New Zealand economy and society, and is reflected in the Ministry of Education's Strategic Business Plan 1998-2001, which emphasises the Ministry's mission to "raise achievement and reduce disparity".

The principal purpose of Government regulation and provision of schooling is to ensure that national social and economic goals are met. To the extent that certain levels of knowledge and skill are required by society and by workers, Government is likely to want to prescribe a national curriculum which ensures that these levels of knowledge and 
skill are specified and that arrangements are put in place to ensure that schools are able to implement a national curriculum effectively, and to be assured that the learning outcomes specified in the national curriculum are achieved and that there is evidence demonstrating this. Given the Government's annual investment of approximately $\$ 2.5$ billion in salaries and schools' operations grants to "purchase" implementation of the New Zealand Curriculum, it is hardly surprising that it wants information on the achievement of students which will enable it to determine the effectiveness of its investment, and in particular the adequacy of its curriculum. Each national curriculum statement contains achievement objectives which describe what students are expected to know and be able to do according to a progressive series of eight levels from Year 1 (New Entrants) to Year 13 (Form 7).

In order to be assured about the extent to which schools meet the goals of Government and community, various mechanisms are written into legislation. These mechanisms consist of different forms of monitoring, including internal monitoring and review, and external reporting and review by other agencies. In these ways, schools are held accountable for meeting the Government's requirements. Schools are required to follow relevant provisions in various Acts, such as the 1989 Education Act (including the requirement to prepare an annual report), the 1989 Public Sector Act and the 1988 State Sector Act to ensure that: the state receives value for money for its investment in education; national education goals are met; and parents can receive assurance that whatever school their child attends they will receive a high quality education. Collectively these provisions describe schools' obligations (through the board of trustees) for governance and management that increase the likelihood that the state's investment in education will be protected.

The Government has specified what boards need to do, through the charter undertaking with the Crown and the national education guidelines. These education guidelines include the following:

1. Boards of trustees must foster student achievement by providing a balanced curriculum in accordance with the national curriculum statements .... In order to provide a balanced programme, each Board through the principal and staff, will be required to:

- implement learning programmes based upon the underlying principles, the stated essential learning areas and skills, and the national achievement objectives; and
- monitor student progress against the national achievement objectives; and

- $\quad$ analyse barriers to learning and achievement; and

- develop and implement strategies which address identified learning needs in order to overcome barriers to students' learning; and

- $\quad$ assess student achievement, maintain individual records and report on student progress; and

- provide appropriate career information and guidance for all students, with a particular emphasis on specific career guidance for those students who, nearing the end of their schooling, are at risk of becoming unemployed.

Schools are required to put in place policies and programmes aimed at ensuring the National Education Guidelines are met.

\section{Current Assessment Policies for Monitoring Student Achievement}

To help schools address these requirements, assessment policies and programmes have been (or are being) developed. Information about student achievement is collected for a variety of purposes. A recent front-page article in the Education Gazette (Eppel, 1998) sets out the various layers of information on student achievement and their associated programmes. Although none of these programmes is compulsory, the information needs of different audiences or stakeholders (e.g., students, teachers/principals, parents, the community and/or Board of Trustees, and Government) vary, and different kinds of information are required to satisfy them.

At this point, it needs to be acknowledged that assessment policy issues have had a high profile in New Zealand for at least a decade. This situation is likely to continue. Since 1989, and well before then, issues to do with the certification of secondary school students' achievement, and the role of assessment activities in supporting students' learning and providing teachers and others with sound information on student achievement, have been debated. The Ministerial Working Party on Assessment for Better Learning, for example, made several recommendations in Tomorrow's Standards: for example, that sampling of educational outcomes take place at two levels (Standard 2 and Form 2 ) in the school system; that all fourth form students each year be assessed on important basic skills using nationally developed tasks and procedures; and that at six years of age every child's progress in 
reading, English and Maori (where appropriate) should be examined. Not all of the recommendations were put in place or in the form recommended.

However, in 1993 The New Zealand Curriculum Framework described the national assessment policy as consisting of several components considered to be integral to the curriculum as a means by which students' progress could be measured against the defined learning outcomes in the national curriculum statements: school-based assessment, assessment at key transition points, records of school achievement, national monitoring of standards, and assessment for qualifications. Since 1993 there have been shifts in policy direction, particularly in relation to assessment at key transition points (now rarely referred to, although the proposal in the Green Paper for national externally referenced tests could be interpreted as an evolutionary development of this), and assessment for qualifications. For the purposes of this paper, developments in relation to school-based assessment, monitoring school effectiveness and national monitoring will be highlighted.

\section{School-based assessment}

Schools need to gather appropriate kinds of information on student achievement to be assured that they are making a positive difference to students' levels of achievement. Schools/teachers can develop their own methods for assessing the progress of individual students against the achievement objectives of the New Zealand curriculum. Although a range of practices is followed, the Ministry has provided schools with assistance to help monitor the progress of individual students, including examples of assessment activities in the national curriculum statements; support materials (for example, Assessment: Policy to Practice issued in 1994); and teacher professional development in assessment through a series of contracts.

School Entry Assessment/Aro matawai Urunga-a-Kura (SEA/AKA) tasks have been designed to provide teachers with an indication of how new entrants perform in basic literacy, oral language and numeracy, through the Assessment for Better Learning contracts. These tasks became available for teachers to use from July, 1997. Professional development to assist new entrant teachers administer school entry assessment was also carried out. School entry assessment has three uses: to provide teachers with valuable diagnostic information about individual children to complement existing assessment information; to provide school management with information about their new entrant cohort for planning and resource allocation within the school; and to inform policy development and monitoring, and resource allocation.

Assessment Resource Banks (ARBs) are also being developed, which can be used to benchmark classroom assessments against the achievement objectives in the national curriculum statements. The Ministry has contracted the New Zealand Council for Educational research (NZCER) to develop banks of standardised assessment items in mathematics, science and English, which are progressively becoming available in computerised format through the World Wide Web on the Internet. Teachers can use the items when they choose, particularly with students in Years 6 to 9. The ARBs were well received by teachers taking part in the trials, although full-scale use of the banks has not yet occurred. The ARBs, which are still being developed and extended, form the current foundation for assessment of students in Years 6 to 9 . Although their use is not compulsory, it is likely that most schools with the necessary computer access will benefit from them as a means to monitor their effectiveness in raising student achievement in relation to the New Zealand curriculum.

Participation in teacher professional development in assessment, and the use of School Entry Assessment and the Assessment Resource Banks is voluntary. None of these activities represents a significant compliance burden for schools, and if they already have sound assessment procedures they can choose to use their own methods. The Ministry is also trying to encourage schools to have more consistent recording and reporting practices for their assessments.

\section{Monitoring school effectiveness}

There are three main ways of monitoring a school's effectiveness, which are complementary: internally, through the school's own policies and practices; external monitoring, mainly through reporting mechanisms described in legislation and audited by the Audit Office; and external review, through an agency empowered to conduct reviews (the Education Review Office).

Internal monitoring by the school (board and principal/staff): Schools adopt internal policies and procedures for monitoring student achievement. The effectiveness with which individual teachers carry this out is one focus of the new Performance Management System. Advice for schools on how to develop sound school-based assessment policies has been provided in Assessment: Policy to Practice supplemented by Managing 
New Zealand Schools: A Guide for Boards of Trustees, focusing on broader issues of how schools can meet the national education guidelines through sound planning and internal review.

The national education guidelines also include a requirement for school boards to document how they are being implemented, and to have a programme of self-review. In order to do this effectively, schools need policies and procedures which ensure that they are monitoring their own practice and able to meet external reporting requirements. Reliable information on student achievement within the school is a key element in this activity, but to inform their self-review, schools also require information which will allow them to monitor trends in the achievement of their students in comparison with national and various subgroup norms. Few assessment tools providing this kind of information are currently available for use before year 11 (School Certificate)

External monitoring, including reporting requirements: As noted earlier, like all crown entities, school boards are required to prepare a Statement of Objectives, an audited financial statement, a Statement of Service Performance and an annual report. Section 41 of the Public Finance Act requires all Crown entities, including school boards, to prepare a financial statement each year. However, section 41A provides for the Minister to exempt schools from the preparation of any of the statements in their annual financial statements provided he is satisfied certain conditions are met. The statement of service performance (SSP) is a statement reporting the classes of outputs produced by a Crown entity during the financial year as compared with the classes of outputs established at the beginning of the financial year and specified in the statement of objectives (Section 41(2)f of the 1989 Public Finance Act). Schools are currently also exempt from preparing the Statement of Service Performance (SSP) under section 41A of the Act, at least till the end of 1999.

Schools need to be able to work towards meeting the expectations which both the Crown and the local community have of them. An effective school is one which meets its obligations to the Crown, with regard to the management of its resources and the production of outputs, and to its community with regard to the education of its children. An effective school allocates funds sensibly in accordance with predetermined priorities and takes steps to improve the learning of all students.
External review by the Education Review Office: The Education Review Office reports publicly on the effectiveness of schools (see Section 325 of the 1989 Education Act). Reporting by ERO provides boards of trustees, the Government and the public with information on schools' compliance with their legal and policy obligations, and their effectiveness in promoting student achievement. The Office reports specify the actions boards of trustees must take in order to meet their obligations, and recommend developments which would improve school effectiveness. ERO accountability reviews are carried out once every three to four years. The ERO visit represents an opportunity for a school to demonstrate its effectiveness to the wider community. For schools needing improvement, the reports provide comments and recommendations to consider in modifying some practices.

Most parents are keenly interested in whether the school their child attends is fostering student achievement. Parents are interested in how a school might cater for their particular child. The Education Review Office plays an important role in providing information for parents and the wider community on the effectiveness of each school through its reviews and published reports; however, little additional information on a school's effectiveness is currently available. Schools are free to implement the national education guidelines in ways that they believe are appropriate. The Education Review Office, however, has indicated that most schools are not using assessment information effectively to inform planning, to evaluate programme effectiveness, or to analyse barriers to achievement.

\section{Monitoring the sector}

At a national level, policy makers need information on how effectively the school system is performing overall, both as a whole and for particular groups, and how this is changing over time and in what curriculum areas. The main mechanism currently used by Government to obtain information on student achievement at a system level is the National Education Monitoring Project (NEMP), which focuses on the achievement in different curriculum and skills areas of a sample of students in Years 4 and 8 . The stated purpose of NEMP, which is carried out on contract to the Educational Assessment Research Unit at the University of Otago, is to provide a national picture of trends in education achievement to assist in policy development, resource allocation and review of the New Zealand curriculum. NEMP provides a comprehensive picture of achievement in particular learning areas, 
covering the whole curriculum over a four year cycle through use of sophisticated (and intensive) assessment procedures.

NEMP has been well-received by schools. It involves a 3 percent sample of all students in the cohorts tested each year. Participating schools and teachers who administer and mark the tasks (released from their normal duties for several weeks) appear to gain considerable benefits through enhanced understanding of assessment procedures. Over time, NEMP will assist in developing the assessment skills of a large number of teachers. Reports from the first three rounds of assessment have now been produced and distributed to schools. However, currently there is no systematic information available on the ways schools use the reports. A fourth round of assessment was carried out towards the end of 1998 and the reports are expected to be available by July 1999. The second cycle of NEMP, when the curriculum areas assessed in the first round will be re-assessed, commences in 1999.

In addition, Parliament needs to have a broad brush overview of how well the education sector is performing in order to inform Cabinet decisions on educational policy directions; the annual report to Parliament on the compulsory school sector from the Minister of Education, New Zealand Schools, partly meets this need. It draws on demographic, financial and achievement data about each school to provide comment on trends in the performance of the school sector as a whole in the supply of outputs, management performance and effectiveness in terms of educational achievement (section 44B, 1989 Public Finance Act). The preparation of this report is undertaken within the Ministry of Education and does not represent a compliance burden for schools. In addition, the occasional evaluation reports produced by the Education Review Office comment on different aspects of the education system.

School Entry Assessment/AKA information, which schools have been invited to send in to the Ministry, will help fill an information gap for the Ministry of Education on the skills and knowledge of the new entrant cohort on entry to school, to inform policy development and resource allocation. The Ministry of Education has also funded the preparation of a national report on the SEA/AKA assessment data (Gilmore, 1999). National baseline data are especially important to enable analysis of the achievement of sub-groups, e.g., to evaluate the progress of Maori students or identify the language competencies of children for whom English is a second language.
In addition, New Zealand regularly participates in international studies focusing on different aspects of student achievement, such as the Third International Mathematics and Science Study (TIMSS), and a new initiative, the Programme for International Student Assessment (PISA), sponsored by the OECD. Information from studies such as these, which compare the achievements of New Zealand students with those in other countries, can assist national policy makers in identifying areas of the curriculum which may need further resourcing.

The Green Paper, Assessment for Success in Primary Schools

On 7 May 1998 the Government published a Green Paper, Assessment for Success in Primary Schools, designed to promote discussion on Government proposals for an assessment package of new resources. The package was developed to provide the teaching profession with the assessment information necessary to establish and monitor expectations of student achievement in relation to the New Zealand curriculum, and to help identify where improvements might be needed. Multiple copies of the Green Paper were sent to every school, with extra copies for interested parents. Each school also received booklets to send to all parents.

\section{Rationale}

It is an often repeated adage that assessment does not of itself contribute to improving educational outcomes for students - better teaching and learning do. Teachers currently undertake much assessment in the classroom, and use a wide variety of assessment activities and tools, such as the Progressive Achievement Tests, developed by the New Zealand Council for Educational Research. But there is a lack of information which can help teachers to gauge the relative effectiveness of their teaching programmes. This makes it difficult for boards, principals, teachers, and parents to identify weak areas and set appropriate targets for improvement.

The Green Paper identified that schools need better information on:

- national expectations of student achievement in relation to achievement objectives, which teachers can use to "benchmark" or check their own professional judgements;

- the performance of their students when compared with aggregated data for groups of similar students nationwide, which schools can use to evaluate the effectiveness of their programmes for specific groups of students within their schools; 
- the achievement trends of subgroups of students.

In addition, many parents are interested in how their child's achievement compares with that of children of a similar age and how well their child is learning in different parts of the curriculum. Government is interested in the effectiveness of its policies and needs sound information which will help in determining where policies need to be reviewed, such as allocation of resources to areas of high need.

\section{Proposals}

The assessment Green Paper set out a proposal for an integrated national assessment package to strengthen and support the assessment activities currently undertaken by teachers, and to alleviate pressures arising from duplicating effort unnecessarily.

It was proposed to develop:

- additional diagnostic tests that teachers can use to provide detailed information on the learning needs of individual students in specific areas;

- national exemplars of student work that would set out assessment tasks with associated samples of student work, along with discussion of how a teacher marked that work and the conclusions the teacher drew about the child's learning in relation to selected achievement objectives. The exemplars would help teachers to decide whether the judgements they are making about student achievement are consistent with national expectations;

- new externally referenced tests to enable teachers to identify how well their students are achieving compared with national and group levels of achievement. This information could help teachers to identify how effective their programmes are for specific groups of students. As proposed, the tests, which would be mandatory, would occur during Years 6 and 8, consist largely of multiple-choice questions, and focus on the essential learning areas of language and mathematics;

- modifications to the National Education Monitoring Project to include in-depth "probe studies" to focus on the achievement of specific groups within the school population. This information would enable Government to identify the achievement of groups of students in order to develop policy and monitor its effectiveness.

The main issue which the Green Paper sought to address was how best to fill the current lack of national information on student achievement at primary school which would allow a school to compare its students' achievement with national and subgroup profiles of achievement for purposes of self-review. All the proposals in the Green Paper were designed with this information need in mind.

\section{Consultation}

The consultation on the Green Paper included: oral feedback from consultation meetings with individuals and key groups; written feedback in the form of formal submissions, some using the response form and others not; completed response forms from parents; written feedback in the form of letters to the Ministers or Secretary for Education about the Green Paper; and advice and comment from the members of a National Assessment Reference Group.

The Associate Minister of Education and officials from the Ministry of Education and the Education Review Office engaged in extensive consultation from early May to mid-August, meeting with people from universities and colleges of education, key assessment experts, principals, key Maori educators, teachers, Pacific Islands groups, and national education organisations. Written submissions on the Green Paper closed on August 7 after a three month consultation period. About 1600 submissions were received. Over 22,000 responses to the parent booklet were also received.

In early August, the Minister and Associate Minister of Education announced that the timeframe for the introduction of national tests had been extended to the year 2000 . The extension of the timeframe for the introduction of the proposed tests was to allow for: further discussion about the most appropriate test model for New Zealand schools; more time for government decisions about the tests to be implemented; more time to consult with assessment experts and practitioners about the design and implementation of a national testing system.

The Education Review Office (1998) also developed its own proposal for national testing, largely based on the notion that teachers would test children when they considered them to be ready to take the test. The Education Forum (1998) advocated testing at age 10. However, neither of these proposals gained much support.

After the launch of the Green Paper, some concern was expressed that government decisions had already been made, and that the Green Paper was not really seeking publicinput. While the purpose of a Green Paper is to set out government policy proposals for public discussion, it is a statement of Government's policy intent. This means that 
government intends to do something of the sort outlined in the paper. The consultation is therefore not around whether to go ahead or not, but is more about how best to shape the policy proposals to enhance teaching and learning.

Diagnostic tools, exemplars of student work and modifications to NEMP Feedback about the development of additional diagnostic tools has been positive, and many examples of diagnostic tools currently used by schools were listed in the submissions. There has been general consensus about the areas where additional diagnostic tools are needed - Maori immersion schooling; literacy in the middle primary years; and mathematics in the middle primary years.

The development of exemplars of student work has been widely supported on the grounds that they will: help teachers to focus on what is important to assess in children's work; help teachers to identify core components of achievement objectives; provide models of good practice, both for developing assessment tasks and for benchmarking at a local level.

However, concerns have been raised that the exemplars of student work could potentially become a de facto curriculum if teachers treat the achievement objectives demonstrated in the exemplar material as the most important ones. Some respondents thought that although "reinventing the wheel" is time-consuming, locally-developed initiatives did mean that teachers had "ownership" of the outcomes, and also gained new professional skills and knowledge during the development process. There was, therefore, some concern that national exemplars could be used to take the place of locally-developed exemplar or benchmarking materials. Priority areas identified for development include mathematics, language (writing, reading and oral language) and science/technology.

The further development of the Assessment Resource Banks (ARBs) to provide more exemplars of assessment tasks has been widely supported. The current contract with NZCER is likely to be extended for a further two years to ensure that more items are available to teachers for assessing mathematics, science and English, mainly at curriculum levels 3 to 5 . However, ways need to be found for encouraging more schools to access and use the banks, and further investigation is needed of ways of combining resources into "intact tests" which schools could administer to provide externally referenced information on their students' achievement. The Ministry has also proposed that an independent evaluation of the banks and their use be carried out.

The Ministry has considered ways of ensuring that NEMP provides information on the achievements of students in Maori-immersion settings, and the possibility of obtaining information on the achievement of subgroups such as Pacific Island students through over-sampling. It is also likely that a range of probe studies will be instigated (funding has been allocated for this) to investigate achievement trends in different learning areas or in relation to different groups of students.

\section{Mandatory national tests}

The proposal for mandatory tests has been seen as inconsistent with the "self-managing school" philosophy, whereby schools decide what resources and systems to use to fulfil the national education guidelines. However, the other side of that philosophy also includes the mandatory New Zealand curriculum which sets national learning outcomes, and the requirements for self-review and accountability to the community for providing effective education. The self-managing school model provides flexibility for schools to meet national education goals in whatever ways they choose. In return for local decision-making about implementation and operational issues, Government has set up tighter requirements for monitoring the outcomes of schooling, as part of schools' accountability to government and the local community. Mandatory national tests are consistent with this approach.

Feedback on the proposal for national tests showed concern about the potential misuse of any test data. While many of those consulted support the underlying purpose of the proposed national tests to provide additional information for school self-review, concerns were raised about the detrimental effects of "league tables" creating "high stakes" testing, such as narrowing the curriculum, teaching to the test, and the placing by parents of undue emphasis on the results. The Ministry of Education agrees that if a test were to assume high stakes status, the effects could be detrimental to teaching and learning. This is why Cabinet agreed that Government would not publish league tables. The challenge now is to work out ways to manage the stakes of whatever policy eventuates following the consultation, to ensure that it can effectively meet its purpose.

Some feedback suggests that teachers would prefer more comprehensive national assessments covering a broader range of 
learning objectives from the curriculum. The tests, as currently proposed, would include only selected language and mathematics achievement objectives which could be assessed using written tests. This includes multiple-choice, short answer and longer, open-ended responses which can assess some performance-based learning. However, there are obviously some performance-based achievement objectives which could not be assessed using pencil and paper tests. If non-written activities were to be included in the tests, teachers would be needed to carry out the assessment tasks in a standardised way, including observing, recording and evaluating the children's learning.

The advantage of testing a broader range of learning objectives using non-written activities is that teachers and principals would obtain a wide range of information about student achievement. This could provide them with more comprehensive indicators of the relative effectiveness of their teaching and learning programmes. One area which was frequently mentioned was oral language. However, a more comprehensive testing programme including an oral language component would involve more testing time for both teachers and students, and more work for teachers in carrying out and evaluating performance-based tasks.

Since any national test would only provide information on a sub-set of learning objectives, it is important to identify what learning can actually be assessed appropriately using standardised tests. Since the tests would only form one part of a much larger picture of student achievement, assessment information from all the other assessments a teacher undertakes would be needed to place the test data in context. It may, therefore, be more appropriate for other areas of learning to be assessed using other tools.

Some respondents suggested that whole cohort testing was unnecessary, and that sampling would be sufficient to provide schools with information on their students' achievement compared with national and group achievement. While this option looks attractive, sampling would mean that only a percentage of students in each school would be assessed. In most schools, the number of students tested would be insufficient for that school to draw any conclusions about overall achievement of that cohort, or of groups within the cohort. An alternative would be for a percentage of schools (say 10\%) to be randomly selected each year to provide an overall national picture, and provide sufficient information on the performance of groups of students based on gender, ethnicity and decile bands. All primary schools would then be able to compare their results against such published national data.

\section{Analysis of the submissions}

The submissions were analysed by an independent researcher from the University of Canterbury (Gilmore, 1998). In general, the findings supported comments made at the consultation meetings held around New Zealand. About 25 percent of respondents either supported or partially supported the proposal for national externally referenced tests. The most common reasons were their potential to provide benchmarks against which the achievement of students of a similar age could be compared, and to provide parents with information on their child's achievement compared with the national picture. Some respondents were supportive, provided that the results would not be published and used for between-school comparisons. However, 73 percent of the respondents did not support externally referenced tests. Some claimed that there was no demonstrated need for additional information. Other reasons reflected concerns that the tests, as proposed, would: have negative effects on children, teachers and schools; have limited validity; foster misleading comparisons and competition among schools; be an inappropriate use of resources; and increase the workload of teachers.

In addition, more than 22,000 responses to the parent pamphlet were analysed (Kerslake, 1999). While these represented only about 5 percent of the pamphlets distributed, the findings indicated that parents/caregivers valued the idea of receiving additional information on their child's progress through primary school. About two-thirds of the respondents supported the notion of literacy and numeracy tests at Year 6 (Standard 4), and about three-quarters at Year 8 (Form 2).

\section{The National Assessment Reference Group}

In order to work towards a preferred option for national testing, the Ministry of Education established a National Assessment Reference Group in early November, 1998. This group of about 20 people consisted of educators such as principals or senior staff and contractors involved with substantial assessment contracts, and met three times before mid-February, 1999. The terms of reference of the National Assessment Reference Group were to:

(a) provide informed comment to Ministry officials on the development of the proposals in the Green Paper, Assessment for Success in Primary Schools; 
(b) advise on models for the development of national tests which meet the policy objectives laid out in the Green Paper and to make recommendations about a preferred option for national testing;

(c) advise on the implications of national assessment for Maori medium education;

(d) advise on technical and other issues which need to be considered in the development and implementation of the national test proposals; and

(e) provide comment on the content of the proposed White Paper announcing final Government decisions on national assessment.

At the first two meetings of the Reference Group, continued opposition to the proposed national tests was expressed. However, a framework for national assessment was outlined as a possible way forward, although this requires further consideration by the Ministry and the issue of which assessment tools would still be needed to help meet the Government's policy outcomes was not resolved. At the last meeting, issues related to the other proposals in the Green Paper were also discussed.

\section{The new Government literacy and numeracy goal}

In October 1998, the Government announced a Literacy and Numeracy Initiative, including the goal that, "By 2005, every child turning 9 will be able to read, write and do maths for success". Teachers will need mechanisms to help them track student achievement towards this goal. Existing tools such as SEA/AKA, the Six-Year-Net and the Progressive Achievement Tests are unlikely to be sufficient on their own. While a new national test for children aged 9 could be developed, other tools are required to assist teachers in monitoring children's progress towards the goal, so that those who are not achieving success can be identified well before they turn 9 and given assistance to improve their learning of language and mathematics.

\section{Towards A More Comprehensive National Assessment Policy}

If schools are to provide a satisfactory account of their core business (e.g., the effectiveness with which they are implementing the New Zealand Curriculum and raising student achievement), and to meet accountability requirements, it seems reasonable that they set objectives annually, show how they are going to meet them and provide an account of the extent to which they have met them. Setting objectives is part of the planning and internal monitoring which could be expected of any soundly functioning organisation, including a school. In the event that Statements of Service Performance or an alternative accountability mechanism are implemented, the targets set for improvement could flow out of a school's activities in evaluating its important objectives for a year or a longer period and not represent an additional, time-consuming activity. Such mechanisms would be a valuable way of helping boards focus on strategic issues and, if used as a mechanism for accounting for the increasing use of formula-driven funding distributed within an undifferentiated bulk grant, could help in monitoring the success of particular Government strategies.

In addition, although there has been little acceptance of the Green Paper proposal for national externally referenced tests, feedback from meetings held with a group of Australian educators from Victoria and New South Wales emphasised the conditions necessary for any national tests to work well: mechanisms must be put in place to prevent results being used to compare or rank schools publicly; the tests must be linked to the New Zealand curriculum; teachers must be involved in the test development process; the results must be useful for teaching and learning, and presented in an informative way; support must be provided so that teachers and principals know how to use the results to enhance learning.

The issue of the role of different kinds of assessment activities has become highly politicised, and in most countries where some form of national testing has been implemented considerable resistance has occurred. However, a major policy issue for governments, particularly those with national or state curricula, is how to benchmark student achievement. Against what standards should their achievement be compared, and should all or the majority of students be expected to meet these standards by a particular age? A related issue concerns the role of various value-added measures for determining the difference which schools are making to students' learning. This is a technically complex area, however, and raises a number of issues about the meaning of the information obtained and what schools can do to improve (see, for example, Fitz-Gibbon, 1996 and Gray \& Wilcox, 1995).

There is also a need for further policy work to establish more effective feedback loops, which would ensure, for example, that information provided by NEMP is used by Government to review its support of schools in specified curriculum areas. In addition, while ERO prepares occasional reports on aspects of the effectiveness of the education system it is not clear how the information is used by the 
Ministry or by individual schools, nor how the information on individual schools collected by ERO could best be used to improve the education system as a whole.

The next step for the Ministry is to analyse the views generated by the Green Paper, the advice of the National Assessment Reference Group and the range of strategies available for achieving the Government's desired policy outcomes. A White Paper setting out the Government's policy decisions will be announced during 1999.

\section{References}

Education Review Office. (1998, Spring). Assessing children's curriculum achievement. Wellington: ERO.

Education Forum. (1998). New directions for assessment at the primary school level. Wellington: Education Forum.

Eppel, Elizabeth. (1998). National assessment policies and programmes. New Zealand Education Gazette, 77(19), 1-2.

Fitz-Gibbon, Carol. (1996). Monitoring education: Indicators, quality and effectiveness. London: Cassell.

Gilmore, Alison M. (1998). Assessment for success in primary schools: Report of the submissions to the Green Paper. Wellington: Research Division, Ministry of Education.

Gilmore, Alison M. (1999). School entry assessment: The first national picture, July 1997-May 1998. Wellington: Ministry of Education.

Government of New Zealand. (1988, May) Assessment for success in primary schools (Green Paper). Wellington: Ministry of Education.

Gray, John, \& Wilcox, Brian. (1995). "Good School, Bad School": Evaluating performance and encouraging improvement. Buckingham: Open University Press.

Kerslake, Jacqui. (1999). Assessment for success in New Zealand primary schools: Parents'/caregivers' views on aspects of monitoring their children's achievement which could impinge upon proposed assessment initiatives for primary schools. Wellington: Research Division, Ministry of Education.

Minister of Education. (1998). New Zealand schools 1997: A report on the compulsory schools sector of New Zealand. Wellington: Ministry of Education.

Ministerial Working Party on Assessment for Better Learning (Chair: Sir James Stewart). (1989). Assessment for better learning: A public discussion document. Wellington: Department of Education
Ministerial Working Party on Assessment for Better Learning (Chair: Sir James Stewart). (1990). Tomorrow's Standards. Wellington: Department of Education.

Ministry of Education. (1993). The New Zealand curriculum framework. Wellington: Learning Media.

Ministry of Education. (1994). Assessment: Policy to practice. Wellington: Learning Media.

Ministry of Education. (1997). Governing and managing New Zealand schools: A guide for Boards of Trustees. Wellington: Learning Media.

Ministry of Education. (1998, June 15). Assessment: Curriculum Development Update 31. Insert in the New Zealand Education Gazette.

Ministry of Education. (1998). Strategic Business Plan 1998-2001. Wellington: Ministry of Education.

Philips, David. (1998, December). National assessment policy and the role of national tests. Paper presented at the annual conference of the New Zealand Association for Research in Education, Dunedin.

\section{The author}

David Philips was recently awarded the degree of Doctor of Philosophy in Education by Victoria University of Wellington for a thesis on policy importation and the development of the National Qualifications Framework. As a Senior Policy analyst in the Learning and Evaluation Policy section of the Ministry of Education, he specialises in assessment policy. During the 1980s at the New Zealand Council for Educational Research he conducted research on the evaluation of children's writing and other assessment topics. 